Revista de Derecho

Universidad Católica del Norte

Sección: Ensayos

Ańo 18 - No 1, 2011

pp. $185-211$

\title{
LAS ADR EN LA JUSTICIA DEL SIGLO XXI, EN ESPECIAL LA MEDIACIÓN*
}

\section{SILVIA BARONA VILAR ${ }^{* *}$}

RESUMEN: El presente ensayo busca exponer en torno a experiencias poco analizadas por los sistemas jurídicos europeos de corte continental, pero muy bien conocidas por los sistemas anglosajones. El objetivo trazado es fomentar el debate en torno a estas alternativas para la resolución de los conflictos en la sociedad, con especial atención a la mediación.

PALABRAS CLAVE: Jurisdicción - mediación - conciliación - arbitraje.

\section{THE ALTERNATIVE DISPUTE RESOLUTION “ADR” IN THE JUSTICE OF THE 21ST CENTURY, ESPECIALLY THE MEDIATION}

ABSTRACT: This essay seeks to expose not very much analyzed experiences by the legal systems of the continental Europeans, but very well known by the Anglo-Saxon systems. The stated goal is to encourage debate on these alternatives to resolve conflicts in society, with special attention to mediation.

KEY WORDS: Jurisdiction - mediation - conciliation - arbitration.

\section{1) SOCIEDAD DEL SIGLO XXI Y TRANSFORMACIÓN DE LA CONFLICTI- VIDAD. CAUCES DE SOLUCIÓN}

Es innegable que, a medida que las sociedades van avanzando y se van desarrollando los individuos que la integran, se genera una mayor conflictividad, tanto por las relaciones de naturaleza individual, cualquiera que fuere su índole, como de naturaleza colectiva o plural. Ello lleva a una inevitable situación en la que aumenta la conflictividad tanto en

Ensayo redactado en el marco del Proyecto DER 2010-17126 (MEC) y Proyecto PROMETEO 2010/095.

Fecha de recepción: 15 de noviembre de 2010.

Fecha de aceptación: 10 de marzo de 2011.

** Doctora en Derecho Procesal. Catedrática de Derecho Procesal, Universitat de Valencia (España), Presidenta de la Corte de Arbitraje y Mediación, Cámara de Valencia. Correo electrónico: Silvia.Barona@uv.es 
cuanto a la cantidad como a la calidad de los conflictos. Y ello exige $-\mathrm{y}$ cuestiona en ciertos casos- que los cauces existentes para evitar y, en su caso, resolverlos, también vayan adaptándose a cada momento, a cada situación, a cada tipo de conflicto y, por supuesto, aparezcan nuevas vías que ofrezcan un mayor abanico de posibilidades a los ciudadanos. En este sentido, nunca como antes se ha mostrado una concienciación tan grande sobre la necesidad de contar con una justicia eficaz como requisito imprescindible para el logro del desarrollo económico de los pueblos y para la consolidación de la paz social. Exigencia que se extiende allende España, convirtiéndose en una preocupación universal. En la búsqueda de este paradigma de justicia eficaz, los tribunales del Estado juegan un papel trascendental, si bien no por ello único y suficiente para alcanzar los resultados pretendidos.

Hemos pasado de conflictos meramente individuales a que afloren los conflictos colectivos e incluso los sociales; hemos pasado de un conflicto entre presentes a un conflicto también entre ausentes, hemos pasado de un conflicto entre nacionales a un conflicto entre personas de diversa nacionalidad, hemos pasado de un conflicto en nuestro país al planteamiento de conflictos en otros países, hemos pasado de conflictos sobre bienes tangibles a conflictos sobre bienes intangibles, hemos pasado incluso a los conflictos entre Estados y a los conflictos interregionales; todo ello sin olvidar el desarrollo de un marco jurídico que lo regula todo, las relaciones personales, comerciales, afectivas, con la administración, con los vecinos, etc. Así, ante una sociedad tecnológicamente en alza, donde los valores sociales priman sobre los individuales, donde la tecnología y la técnica se han hecho omnicomprensivas, haciendo evolucionar los parámetros de comportamiento de los ciudadanos, y en la que la reglamentación administrativa va en ascenso, con un imparable aumento de la litigiosidad, no solo nacional sino también transfronteriza, los tribunales se han venido manifestando inoperantes como único cauce para responder ante los mismos.

Todos estos elementos, entre otros, complican, cuando no imposibilitan, una solución de los conflictos jurídicos que se alcance de manera racional, tanto en lo referente al tiempo, como al coste de la misma. En el deseo de buscar fuera de los órganos jurisdiccionales o en el seno de estos, de forma complementaria, una solución efectiva, rápida, discreta y más pacífica a los conflictos jurídicos se ubica el movimiento de las ADR articulado inicialmente a través de "mecanismos que intentan resolver disputas, principalmente al margen de los tribunales, o mediante medios no judiciales"1. Un movimiento que, tal como vino a disponer la misma Reso-

Cappelletti, M. (1993). "Alternative Dispute Resolution Processes Within the Framework of the World-Wide Access-to-Justice Movement", Modern Law Review, p. 282. 
lución de la Asamblea General de las Naciones Unidas de 19 de noviembre de 2002 en relación con la Ley Modelo de la CNUDMI ${ }^{2}$ sobre Conciliación Comercial Internacional ${ }^{3}$ está teniendo un imparable desarrollo en los últimos años en los países económicamente más desarrollados del planeta: "esos métodos de solución de controversias, a los que se alude con expresiones tales como conciliación y mediación y términos similares, se usan cada vez más en la práctica mercantil nacional e internacional en sustitución de los litigios judiciales". Unos medios, en suma, cuyo uso "produce beneficios importantes, pues reduce los casos en que una controversia lleva a la terminación de una relación mercantil, facilita la administración de las transacciones... por las partes y da lugar a economias en la administración de justicia de los Estados", contribuyendo, además, a generar un marco de seguridad jurídica que facilita el desarrollo de unas relaciones económicas nacionales e internacionales armónicas.

En ese contexto, la evolución ha sido imparable y, dejando a un lado aquellos supuestos en que el ordenamiento jurídico ha querido restringir o privar la capacidad del ciudadano de gestionar los conflictos, convirtiéndolo en tema de interés público o general -ámbito que, por otra parte, se ha venido restringiendo en los últimos tiempos- cuando surge un conflicto los ciudadanos podemos asumir diversos planteamientos:

1. En primer lugar, es indudable que los ciudadanos pueden "aguantar" su conflicto, a saber, mantener una posición pasiva ante el mismo, no reaccionando ni buscando una solución que permita resolverlo. Es su libertad la que decide que así sea.

2. En segundo lugar, pueden tratar de resolverlo a través de un acuerdo o consenso inter partes.

3. En tercer lugar, iniciada la gestión para obtener una solución al conflicto, y no pudiendo llegar a un acuerdo, las partes pueden acudir a un tercero, que les ayude ora a gestionar el conflicto, ora a resolverlo, imponiéndoles la solución. Pueden agruparse, y así lo hacen los ordenamientos jurídicos, atendiendo a la función de quienes intervienen en la gestión o solución del conflicto, las diversas vías en dos grandes apartados:

Por un lado, la autocomposición, que supone que el tercero que interviene lo hace inter partes, ayudando a las partes a que sean estas las que definitivamente alcancen el acuerdo que ponga fin al conflicto. Son por

Comisión de las Naciones Unidas para el Derecho Mercantil Internacional.

Asamblea General de N.U. quincuagésimo séptimo período de sesiones. Suplemento No 17 y correción (A/57/17 y Corr. 1), anexo 1. 
ello los mismos sujetos en conflicto los que, con ayuda del componedor, van a alcanzar una solución a las diferencias existentes, autocomponiéndose ellos mismos a través de una solución más o menos consensuada. Se parte de una idea básica de considerar que es mejor un acuerdo, que se obtiene mediante cesiones recíprocas de ambos, que una solución que un tercero impone a las partes. Son diversas las fórmulas existentes, de manera que es posible que el tercero tenga una mayor o menor intervención en la búsqueda del acuerdo, permitiendo con mayor intensidad que estas alcancen este. Es por ello que es posible hacer referencia a la mediación, o a la conciliación, entre otras.

Por otro lado, la heterocomposición, que implica que el tercero que actúa lo hace supra partes, esto es, impone la decisión a los que acuden al mismo para alcanzar una solución, en la que no toman parte los sujetos implicados sino que es decisión del tercero ajeno al conflicto mismo.

Las dos vías heterocompositivas que se conocen en los ordenamientos jurídicos son el proceso judicial, en el que es el juez el que impone la solución a quienes acuden al mismo, o el arbitraje, que es un proceso en el que el árbitro es designado para resolver, igualmente de forma imperativa, el conflicto sometido al mismo. En ambos casos existe la alteridad en la resolución del conflicto, existe proceso, existen partes y garantías de contradicción a las mismas, amén del respeto debido a principios como el de igualdad.

Con este panorama la situación en la actualidad tiende hacia la pluralidad, de manera que frente a una situación de extrema jurisdiccionalidad y judicialidad, especialmente en sistemas jurídicos como el nuestro, nos hallamos ante un momento en el que es más interesante -y el Estado así lo ha percibido igualmente- ofrecer una pluralidad de cauces que permitan escoger en libertad la opción más adecuada en cada momento y en atención a las circunstancias que concurren y al tipo de disputa de que se trate. En este paradigma de justicia eficaz, el arbitraje, la mediación, la conciliación y demás instituciones que se incardinan dentro del denominado movimiento Alternative Dispute Resolution, hoy Adequated Dispute Resolution ( $A D R$ ), han alcanzado un protagonismo sin parangón anterior en la historia. Nunca como hoy se ha tomado conciencia de las posibilidades que estos mecanismos ofrecen como vía complementaria, que no ya necesariamente alternativa, a la justicia estatal con vistas a consolidar un sistema de evitación, y en su caso, de resolución de conflictos plenamente satisfactorio para el ciudadano, en particular, y para la sociedad en su conjunto. Esta creciente concienciación se hace patente -como se ha manifestado- tanto en nuestro país como fuera de nuestras fronteras. 


\section{2) DE LA JURISDICCIONALIZACIÓN DE LAS SOCIEDADES OCCIDENTA- LES A LA POTENCIALIDAD DE LAS ADRS}

Frente a un claro fenómeno de la jurisdiccionalización de las sociedades modernas a lo largo del siglo XX, la etapa de la globalización y de la modernidad ha venido marcada por una necesidad imperiosa de buscar nuevos cauces, vías y medios que permitan ora desconflictivizar la sociedad, ora aprender a gestionar los conflictos, ora resolverlos de forma lo más pacífica y menos traumática posible. En ese contexto la evolución ha sido trascendental y en gran medida las respuestas que se ofrecen son la consecuencia inmediata de la realidad existente, tanto social, económica como políticamente establecida.

Muchos han sido los motivos de este fortalecimiento y protagonismo del Poder Judicial en la vida jurídica, que se ha hecho palmario tanto en las relaciones jurídicas personales, como en las que trascienden a estas y se adentran en el marco de las relaciones económicas, amén incluso en las propias que se han ido conformando en la misma vida jurídica pública. En este sentido, el aumento imparable de la conflictualidad social, en todos los sectores de las relaciones jurídicas, en parte por el desarrollo social, cultural y económico de los pueblos, ha provocado un claro ensanchamiento del mismo sistema legal, auspiciando, cada vez más, la conformación de relaciones jurídicas desconocidas hasta el momento, apareciendo lo que ha venido expresivamente denominándose como la juridificación creciente de la vida social en su conjunto, provocándose, a este respecto, el uso, cada vez más generalizado, de los diversos instrumentos que el sistema pone en manos de los ciudadanos, de los grupos, de las personas jurídicas, etc.

Esta situación ha provocado, a su vez, una extensión omnipresente de la regulación jurídica y con ella de una presencia ubicua del Poder Judicial, de los tribunales, que extienden sus tentáculos, en cuanto a ámbito de actuación se refiere, a todos los posibles espacios jurídicos. Es por ello que la regularización jurídica de todos los acaecimientos y actos de la vida han provocado un efecto expansivo de la tutela jurisdiccional. Las consecuencias del mismo, sin embargo, eran impredecibles y la inoperancia en ciertos casos del sistema judicial en su conjunto no se han hecho esperar.

No puede, asimismo, negarse que la ideología política ha marcado de forma palmaria ese protagonismo del Poder Judicial en la sociedad actual. Los grandes acontecimientos históricos de los siglos XVIII, XIX, y XX han sido fruto de los movimientos ideológicos, asentamientos y derrocamientos políticos, que han incidido asimismo y de forma innegable en la configuración, estructuras y funciones propias del Poder Judicial; poder, en todo caso, no en el sentido moderno del término y conceptualizado como uno de los tres poderes del Estado, sino en su significado maximalista de administración de justicia o justicia en general. Repárese que ni 
tan siquiera en la actualidad existe unanimidad conceptual en torno a la Justicia e incluso al papel que la misma desempeña en la sociedad moderna. No obstante, la amplia variedad de sistemas judiciales democráticos responden a dos grandes modelos:

Por un lado, el modelo jacobino, fruto de la Revolución francesa de 1789, que parte de la existencia de una sola fuente de poder, la voluntad del pueblo, y solo un medio a través del cual manifestarse la misma externamente, que es el Parlamento. La concepción mantenida por los revolucionarios franceses pretendió acabar con el sistema judicial del Antiguo Régimen. El papel del juez se reduce a la aplicación de la ley, o, en palabras de Montesquieu, "el juez es la boca que pronuncia las palabras de la ley". Desde esta concepción el juez no es representante de la voluntad popular sino un funcionario, si se quiere cualificado, a quien se le encomienda un servicio público de especial importancia. Sin embargo, el Poder Judicial era invisible o nulo, lo que llevaba a afirmar en realidad que para esta concepción no existía un verdadero Poder Judicial.

Por otro lado, el modelo estadounidense partió de la misma premisa -no hay más fuente de poder que la voluntad popular- si bien la misma puede expresarse a través de tres medios diversos, empero con posibilidad de serlo concurrentes, a saber, los poderes Ejecutivo, Legislativo y Judicial. El origen de este modelo arranca de la Revolución Americana de 1776, que provocó el nacimiento de los Estados Unidos. La configuración del sistema judicial americano pretendió en sus inicios ser una apuesta contra el sistema de Common law heredado del Reino Unido en la época colonial, aun cuando es indudable que los principios esenciales del sistema inglés permanecieron inalterados ${ }^{4}$. Quizás lo más destacable fue la impronta revolucionaria obstinada en atribuir al juez la función interpretadora de las normas, amén de velar por la primacía de la supreme law of the land, a saber, la Constitución. Desde esta concepción sí tiene sentido hacer referencia al "poder" judicial, al ubicarlo en el mismo

4 Interesante a este respecto es el estudio de Toharia, J.J. (2001). Opinión pública y justicia, Madrid: Consejo General del Poder Judicial, pp. 39-40, refiriéndose expresamente al dato de que "Gran Bretaña no era ciertamente, en 1787, una monarquía absoluta como las predominantes en el continente; por supuesto, tampoco era aún una democracia (al menos según los standars establecidos por las revoluciones francesa y americana), pero llevaba ya largo tiempo-como minimo desde comienzos del siglo XVII- evolucionando inequivocamente en esa dirección. No parece necesario recordar, por ejemplo, que fue de la pluma de Locke, en 1690 (Cap. XI, \&134) y no de la de un philosophe o de la de un tribuno revolucionario de un siglo más tarde de donde salió la siguiente proclama, quintaesencia de lo que sería el espiritu revolucionario democrático: "ningún edicto u ordenanza, sea de quien sea, esté redactado en la forma en que lo esté y cualquiera que sea el poder que lo respalde, tienen la fuerza y el apremio de una ley si no han sido aprobados por el poder legislativo elegido y nombrado por el pueblo. Porque sin esta aprobación la ley no podría tener la condición absolutamente indispensable para que lo sea, a saber, el consenso de la sociedad, puesto que nadie existe por encima de ella con poder para hacer leyes, sino mediante su consentimiento y con la autoridad que esa sociedad le ha otorgado". 
origen y sometido a los mismos mecanismos básicos de control que los otros poderes.

Así surgen los dos grandes modelos. El modelo francés, nacido en la Revolución francesa y moldeado en la época del imperialismo napoleónico, se extendió por el continente europeo y por América Latina, si bien con las adaptaciones oportunas que han ido configurando la idiosincrasia propia de cada uno de los sistemas jurisdiccionales nacionales. Y el modelo del Common Law, atribuyendo al juez un papel mucho más creativo en su función jurisdiccional, provocando a estos efectos lo que se ha venido denominando como la realización jurisdiccional del derecho.

El siglo XX ha representado en la historia de la humanidad el fortalecimiento del Estado, en ocasiones autoritario o totalitario, y desde el que era lógico concebir que la mejor solución a los conflictos de los ciudadanos era el propio Estado, que ofrecía "sus" órganos jurisdiccionales y "su" proceso como los cauces más adecuados para alcanzar la solución y tutela de los ciudadanos. Esa situación se vivió en España de forma acuciante a lo largo del siglo XX y especialmente a finales del mismo. Repárese que en este contexto se hacía necesario, especialmente tras las dictaduras europeas y latinoamericanas, la consagración de un Poder Judicial en el marco constitucional para alcanzar la tutela judicial efectiva de todos los ciudadanos. El camino hacia las democracias sociales, en las que el Estado ha ido asumiendo la tutela del ciudadano y ofreciendo políticas proteccionistas ha tenido también su reflejo en la Justicia, en el Poder Judicial.

Pero precisamente ese fortalecimiento del Poder Judicial, unido a los factores exógenos, económicos, culturales, sociales, sociológicos, tecnológicos, etc., han ido convirtiendo en inoperante el mismo Poder Judicial para ofrecer solución a cuantas pretensiones y conflictos se han ido cuestionando ante los órganos jurisdiccionales. Repárese que no se trata de afirmar que el Poder Judicial no sirve, sino que, antes al contrario, este ha sido reforzado, potenciado, auspiciado y utilizado, quizás en este caso en demasía, en cuanto el ámbito de la jurisdicción ha experimentado un proceso expansivo. Hemos asistido al omnipresente protagonismo del Poder Judicial en la vida jurídica de los ciudadanos, llegando a la imposible operatividad del mismo. Las consecuencias de ello se han dejado sentir, adentrándonos en una búsqueda de otros medios que permitan la tutela de los ciudadanos en el marco de las soluciones extrajurisdiccionales.

Precisamente, en el deseo de buscar fuera de los órganos jurisdiccionales o en ellos pero de forma complementaria la solución a los conflictos jurídicos se ubica el movimiento de las ADR (Alternative Dispute Resolutions). La aparición de las ADR se produjo en los EE.UU. hacia la década de los años treinta del siglo pasado, como consecuencia de otro movimiento, típicamente anglosajón, denominado movimiento de libre acceso a la justicia, que pretendió asegurar que todos tuvieran la posibi- 
lidad de acceder a un medio, cualquiera que este sea, que permita efectivamente conseguir una solución al conflicto planteado. Ese movimiento de libre acceso a la justicia se dirigió a la búsqueda de alternativas a los tribunales; alternativas, muchas de ellas, en absoluto desconocidas en el sistema jurídico. Las razones que en su día facilitaron un desarrollo de estos cauces fueron varias, abarcando desde el colapso que se había venido produciendo en los órganos jurisdiccionales civiles y penales, incapaces de hacer frente a los asuntos que diariamente venían engrosando el quehacer judicial, hasta el sentimiento creciente de que faltaban mecanismos privados de resolución de las controversias, sobre todo cuando de conflictos jurídicos entre particulares se refiere, pasando por la incapacidad intrínseca del sistema de poder asegurar a todos el acceso a la justicia, a través de las plurales vías que pueden desplegarse para la obtención de la misma ${ }^{5}$. Argumentos, todos ellos, que curiosamente perduran, si no es que se ven incrementados, en nuestros días.

Todos estos datos, unidos a los acontecimientos producidos en los EE.UU. tras el famoso 24 de octubre de 1929, denominado "jueves negro”, en el que lo que se produjo fue la mayor crisis económica mundial, generando la depresión de los años treinta, la intervención de los EE.UU. en las dos guerras mundiales, y la inestable situación laboral, penitenciaria, migratoria, económica y social producida en esa década y las que le siguieron, provocaron una necesidad de buscar, primero con carácter voluntarista, particular o colectivamente, y posteriormente con intervención misma del Estado, esas plurales vías de solución de los conflictos. La extensión del movimiento ADR en Estados Unidos es hoy total, coexistiendo con $-\mathrm{y}$ complementando cada vez más- el recurso a los tribunales estatales. Sirva un dato paradigmático a modo de ejemplo: la constitución tras el desastre motivado por el huracán Catrina, a finales del 2005, del Mississippi Hurricand Mediation Program $Q \& A$ creado por el propio Estado de Mississippi y que a partir de la asunción de la imposibilidad de los tribunales estatales de resolver el inmenso número de litigios surgidos en el sector, por ejemplo, de los seguros domésticos, busca fomentar el recurso a la mediación estableciendo modelos al efecto. Esta sensación de imposibilidad de hacer frente -tanto desde la perspectiva de los medios personales, materiales o financieros- a la necesidad de justicia que una sociedad cada vez más dinámica y compleja reclama en nuestros días es la que fundamenta la actual tendencia creciente imparable de los mecanismos de ADR buscando imbricarlos en la noción misma de administración de justicia.

Twining, W. (1993). "Alternative to What? Theories of Litigation, Procedure and Dispute Settlement in Anglo-American Jurisprudence: Some Neglected Classics", Modern Law Review, p. 380. 
El origen marcadamente anglosajón del movimiento ADR y esa evolución aceptada y asumida en el modelo americano de justicia, no han sido óbice para que las ADR hayan ido adentrándose de forma imparable y constante en otros sistemas jurídicos de la más variada naturaleza. La introducción y evolución de las mismas en otros modelos distintos del americano se ha desarrollado, empero, por otros derroteros, atendidas las diversas realidades jurídicas nacionales. De este modo, por un lado, la cultura jurídica del litigio ha sido una constante en muchos países occidentales, básicamente, todos los que tuvieron su origen en el derecho romano y que posteriormente pasaron a conformar el modelo continental (países latinoamericanos y aquellos países europeos que no asimilaron el sistema del Common Law); en ellos se ha potenciado esa cultura del litigio desde la ley y desde la práctica misma, amén de que las instituciones (Colegios de Abogados, Judicatura y Universidad) han sido las grandes transmisoras de que conflicto y resolución del conflicto equivalía, y todavía en países como el nuestro equivale, a acudir a los tribunales. España y Chile constituyen claros exponentes de esta concepción. Por otra parte, también los avatares políticos que acompañaron la historia de gran parte de estos países durante los siglos XIX y XX han afectado al desarrollo y extensión del movimiento de las ADR. Un número importante de los países latinoamericanos y europeos se vieron marcados por guerras, dictaduras, cambios de régimen político (repúblicas-monarquías)... Una inestabilidad que pedía un fortalecimiento del Estado en todos sus ámbitos y por ello era impensable concebir de tutela de los ciudadanos (que, en la mayoría de los casos no eran ciudadanos sino administrados "sometidos") por cauces diversos de los que el Estado proponía y conformaba. En suma, pareciera como que al Estado le preocupaba más cambiar sus estructuras y la cultura judicial, dejando atrás las depuraciones, las corrupciones, la incredulidad en el mismo, que buscar, potenciar y, a la postre, favorecer lo que no fueren cauces estatales de resolución de los conflictos. Esa figura del Estado protector se hallaba por ello presente en ese momento concreto.

Esa situación descrita, sin embargo, ha ido cambiando de forma generalizada en los últimos años. Si bien los sistemas continentales siguen respondiendo a unas coordenadas judicialistas, la evolución política, la consolidación de las democracias y con ellas del fortalecimiento del Poder Judicial, han venido acompañadas de todo un conjunto de desarrollos sociales, jurídicos y políticos que han puesto de manifiesto, por un lado, la pervivencia de la denominada "crisis" de la justicia, plasmada en la existencia de un sistema de justicia estatal que resulta desbordado, inoperante, como fenómeno global y universal, y que pervive en un entorno de creciente litigiosidad social. Y por otro, una difuminación de las diferencias existentes entre los modelos jurídicos del sistema continental y el sistema del common law, acompañada de la presencia en los países de corte continental de una cierta fascinación por el modelo de common law, 
en el que el movimiento de las ADR sigue contando con un vigoroso crecimiento y en el que se habla sin tapujos del hecho de que "the long-term trend towards the privatization of dispute resolution is a social and cultural reality" 6 , al menos, hemos de añadir nosotros, en ciertos ámbitos de la realidad social.

Es por ello que un análisis somero de la situación de las ADR en los países de nuestro entorno pone de manifiesto la existencia de un recurso sistemático y generalizado por parte de diversos sectores sociales al conjunto de instrumentos incluibles en estos ADR respecto de disputas del más variado signo y sentido: materias comerciales -nacionales e internacionales-, sistema bancario y financiero, cuestiones de consumo, seguros, turismo, energía, construcción, propiedad industrial e intelectual, relaciones laborales, deportes, salud, ocio, cuestiones comunitarias, electorales o de familia, son algunos de los ámbitos cubiertos por estos mecanismos. Se ha producido, pues, una generalización del recurso a los diversos mecanismos del ADR en gran parte de los países del mundo, variándose su proyección en la práctica - de su consideración como una realidad exclusivamente "out of Court" se ha pasado crecientemente a resaltar su potencial "in Court"-, y ampliándose sobremanera los ámbitos susceptibles de ser cubiertos por el movimiento: de esta suerte, del sector del Derecho privado se ha pasado de forma creciente al del Derecho público, de los litigios nacionales, también a los internacionales y de los conflictos jurídicos a otro tipo de conflictos y litigios con una marcada dimensión social: los estudios de la UNESCO con respecto al uso de estas técnicas de ADR en la gestión y resolución de los conflictos en relación con el uso del agua es todo un síntoma en esta línea ${ }^{7}$. Todo apunta, además, a que el proceso, lejos de estabilizarse va a acelerarse en el futuro inmediato: la mención que realiza el Tratado de Lisboa al fomento de las ADR como uno de los objetivos de la Unión Europea en el ámbito de la cooperación judicial (art. 81 del recientemente entrado en vigor Tratado de funcionamiento de la UE, anterior Tratado de Roma) es paradigmática en tal sentido.

Es así por ello que -debemos insistir- no se trata de imponer de forma coercitiva el empleo de estos cauces, máxime si se asume que el sustento de ellos no es otra que la libertad, la voluntad del ciudadano de querer acudir a quien no es juez para tratar de resolver sus conflictos, suavizarlos o mermarlos, en aras de una búsqueda de paz individual y social. El paso esencial es el de la convivencia pacífica entre las soluciones jurisdiccionales y las soluciones extrajurisdiccionales. No se trata, por ello, de buscar huidas del Poder Judicial, cuanto de mecanismos complementarios

6 Lipsky, D.B. \& Seeber, R.L (2004). "Dispute Resolution in the Changing Workplace”, en IRRA Proceedings of the 57 Annual Meeting.

7 Shamir, Y. (2003). Alternative Dispute Resolution Approaches and Their Application, UNESCO, Technical Documents in Hydrology, PC-CP Series nº 7. 
e incluso en ciertos casos integrados en el mismo sistema judicial, con el fin de buscar la solución integral más acorde a la materia, conflicto, sujetos, tiempo, etc. De ahí que se afirme que en todos ellos subyace el espíritu confuciano de la búsqueda de la persuasión por encima de la coacción. Es por ello que los sistemas anglosajones, modélicos en este ámbito, han venido elaborando programas de ADR dentro de los tribunales, de manera que casi todos los juzgados de distrito de carácter federal fueron asumiendo alguna fórmula de resolución de conflictos ${ }^{8}$, estimulando la incorporación de mediación, arbitraje o fórmulas mixtas en ellos. La década de los noventa del siglo XX se caracterizó en los EE.UU. por la aprobación de las Acts, que han venido conteniendo normas sobre actuaciones conjuntas en los mismos juzgados así como mandatos para expandir el uso del ADR desde los tribunales?.

Sin embargo, no todos estos datos son positivos. Esta situación de creciente fomento de las ADR en la mayoría de los países del mundo contrasta con la aparición de ciertas actitudes radicalmente contrarias a la misma en algunos países de Latinoamérica. La nueva Constitución boliviana de 2009 o determinadas reformas legislativas que se están desarrollando en Venezuela - proyecto de Ley Orgánica del sistema de Justicia y la Sentencia de la Corte Constitucional de 12 de agosto de 2009 en relación con ella- mantienen una posición radicalmente favorable al monopolio de la justicia "estatal". Se trata, esencialmente, de actitudes directamente afectadas por la realidad del arbitraje en materia de protección de inversiones, que aunque son todavía minoritarias, pueden reflejar una tendencia diferente a la mantenida en la mayoría de los países desarrollados de los cinco continentes, que debe tenerse presente. Y, curiosamente, más por un desconocimiento de la propia realidad y significado del empleo de las $\mathrm{ADR}$ en el ámbito de la solución de conflictos y de la puesta en marcha de un nuevo modelo de justicia moderno se aplica la misma animadversión a cualquiera de las otras vías que no sean las que controla de forma directa el Estado autoritario.

En España la falta de un marco regulador y de ausencia de una cultura negociadora y de pacto lastraron una perspectiva nada halagüeńa para las ADR. Y esta situación se vio si cabe más reforzada con la aprobación de la Constitución espańola de 1978 que asumía como uno de los pilares esenciales del estado social y democrático de derecho un verdadero Poder Judicial, fuerte, con credibilidad, que otorgaba confianza a los ciudadanos, y no "administrados". Esta perspectiva era bien negatoria de una posible tendencia hacia la salida del poder judicial. Ello no ha sido óbi-

Singer, L.R. (1996). Resolución de conflictos. Técnicas de actuación en los ámbitos empresarial, familiar y legal, Buenos Aires: Paidós, pp. 22-23.

9 Katz, L.V. (1993). "Compulsory alternative dispute resolution and voluntarism: two-headed monster or two sides of the coin ?", en Journal of Dispute Resolution, p. 17. 
ce, sin embargo, de la situación actual, que parece ir cambiando a pasos agigantados. Tanto el CGPJ como las autoridades políticas -Ministerio de Justicia y Consellerías de Justicia autonómicas- están totalmente convencidos de la necesidad de dar el paso hacia algo más. Y en ese algo más, en ese Modelo nuevo de Justicia del siglo XXI hay que apostar por una transformación, que comporte una redistribución y reorganización de los medios, materiales y personales, amén de la incorporación de nuevos instrumentos de gestión que, desde las nuevas tecnologías y con una oficina judicial en condiciones, favorezcan, agilicen y resuelvan la situación de colapso que existe en ciertos ámbitos y en ciertos órganos de la administración de justicia. En ese modelo nuevo de justicia del siglo XXI están necesariamente involucradas, como vías a incorporar en el propio apartado de la Justicia que se presenta por los poderes públicos al ciudadano, las $\mathrm{ADR}$, tanto las clásicas, como las que han ido evolucionando en modelos jurídicos de nuestro entorno algo más avezados en la cultura pactista.

Por su parte, en el plano comparado se constata la presencia y el vigor de esta tendencia: las propuestas legislativas que diversos países del mundo están preparando al respecto, se combinan, en el seno de la Unión Europea con la admisión del "desarrollo de métodos alternativos de resolución de litigios" como uno de los objetivos de la Unión que incorpora el Tratado de Lisboa, o con la aprobación de la Directiva 2008/53/CE del Parlamento Europeo y del Consejo de 21 de mayo de 2008 sobre ciertos aspectos de la mediación en asuntos civiles y mercantiles en el marco de la Unión Europea. Significativos resultan, igualmente, los trabajos desarrollados por Naciones Unidas en este ámbito; así, por ejemplo, la elaboración de la Ley Modelo de la CNUDMI sobre conciliación comercial internacional de 2002, o la reforma de la Ley Modelo de la CNUDMI sobre arbitraje comercial internacional concluida en junio de 2006.

La lectura de todos estos datos objetivos refleja de forma palmaria la trascendencia de un movimiento dotado de una generalizada extensión geográfica y material, así como de una enorme actualidad y relevancia jurídica, social y económica. Su importancia, empero, es muy superior; va allende estos datos. La actual extensión del movimiento ADR abre un amplio futuro, a la vez que genera, lógicamente, una pluralidad de riesgos para este. La aceptación de los mecanismos ADR como complemento del modelo tradicional de justicia articulado en los últimos siglos en torno a los tribunales estatales, y la consiguiente admisión del recurso a estos instrumentos en sectores donde nunca antes se pensó que podrían ser utilizados -la mediación penal o la incipiente utilización del arbitraje en el ámbito tributario e, incluso, administrativo, son ejemplos de ello- favorece, a la vez que exige, una profunda reflexión sobre el futuro de la justicia y de la administración de justicia en estos momentos. Casi sin ser conscientes de ello estamos viviendo un momento crucial para el entendimiento de lo que significan estos dos conceptos y para su articu- 
lación práctica. Ya no se trata de diseñar - una vez más- mecanismos que permitan reducir la litigiosidad o aligerar la tarea de los tribunales. La actual tarea $-\mathrm{y}$ el reto que incorpora- va más allá. Nos encontramos en un momento decisivo en el que se están sentando las bases de lo que será el entendimiento de la administración de justicia del futuro. Una justicia, la del siglo XXI, que previsiblemente va a variar en profundidad respecto de la que se ha venido desarrollando hasta el momento y en el que los mecanismos ADR, como fenómeno global de la realidad socioeconómica de la segunda mitad del siglo XX, van a constituir un elemento esencial de la misma... con todos los cambios que ello acarrea.

\section{3) MODALIDADES DE ADR, EN ESPECIAL EL IMPULSO POR LA MEDIACIÓN}

Si como apuntábamos supra, en el marco de las ADR debe considerarse necesario atender a las dos funciones que se cumplen a través de los diversos cauces y al papel que el tercero que interviene ejerce en los mismos, es necesario diferenciar entre la heterocomposición, en la que el tercero impone su decisión y lo hace como un juez, fundado en la misma autonomía de la voluntad con fuerza de cosa juzgada su decisión -proceso arbitral-, y la autocomposición, en la que el tercero no se halla supra partes sino inter partes, no hay imposición a las partes, sino que son estas las que acuerdan llegar a puntos de encuentro o a una solución consensuada del conflicto; en este ámbito autocompositivo lo que prima es la búsqueda de las soluciones pacíficas, evitar la escalada del conflicto y trabajar con las partes, en unos casos más intensamente que en otros, para alcanzar una solución o una buena gestión del conflicto existente. Históricamente fue la conciliación la figura que de forma universal se acogió en los ordenamientos jurídicos, como manifestación autocompositiva por excelencia, si bien en los últimos tiempos ha cobrado fuerza la incorporación en los mismos de la mediación, cuyas coordenadas son diversas a las de la conciliación.

\section{(3.1) LA CONCILIACIÓN}

Se trata de una figura que ha convivido durante largas épocas de forma muy amistosa con el proceso civil y el proceso laboral, inclusive alcanzando acuerdos interesantes, especialmente en el orden laboral, que permiten la no existencia de un proceso posterior. Y ello sin desdeñar la existencia de la conciliación igualmente en materia penal y administrativa, aun cuando en ciertos casos sucede que indistintamente se le denomina mediación o conciliación, si bien no son lo mismo, producto precisamente de la función que llevan a cabo el mediador y/o el conciliador, dado que si bien el mediador trabaja con técnicas de aproximación 
de las partes, interviene de forma palmaria pero visibilizando la posición de ambas partes en la búsqueda de la solución al conflicto, en el caso de la conciliación este llega a proponer soluciones inclusive y no trabaja conjunta y separadamente con las partes para que sean estas las que asuman el verdadero papel en el acuerdo.

En todo caso es posible que distingamos diversos tipos de conciliación en atención al momento procesal en el que la misma se produce, cuando existe o puede existir proceso de forma evidente: En primer lugar, la conciliación es preprocesal cuando se produce antes de que el proceso se haya iniciado. En segundo lugar, la conciliación es intraprocesal cuando se produce pendiente el proceso mismo, de manera que existe un intento de alcanzar el acuerdo aun cuando ya se han pergeñado las posiciones procesales de las partes. En tercer lugar, la conciliación es postprocesal cuando se desarrolla tras la finalización del proceso, siendo inclusive posible en la fase de ejecución.

En el ordenamiento jurídico español, por ejemplo, desempeñó, siquiera de forma presente, un papel visible la conciliación en el ámbito civil, y durante largas etapas fue obligatoria la misma, desapareciendo en 1984 la obligatoriedad, dado que se había convertido en un mero escalón más que había que necesariamente pasar para poder continuar con el proceso. En la actualidad la LEC/2000 ha venido a regular un intento de conciliación en la audiencia previa (arts. 414 y ss), que convive de igual modo con la regulación de la conciliación preventiva que se mantuvo tras la aprobación de la LEC/2000, tal como se regulaba en la Legislación procesal de 1881, pero con las modificaciones actualmente introducidas por la Ley 13/2009, de 3 de noviembre. En los restantes órdenes sigue teniendo presencia, con mayor o menor intensidad, la conciliación, tanto en el ámbito laboral (la judicial y la que se lleva a cabo por el SMAC) como en el ámbito administrativo, prevista en la LJCA, como inclusive la penal, que se va a desarrollar como conciliación previa en el caso del delito privado.

Habría que plantear por qué, aun manteniéndose como tal institución, ha perdido importancia en el marco de las ADR. Podría afirmarse, en tal sentido, que el desarrollo de otros procedimientos diversos a la conciliación en aquellos ordenamientos en los que las ADR alcanzaron empuje hace ya algunas décadas, llevaron a perfeccionar la conciliación, eliminando de ella aquellos elementos que, en el fondo, la llevaron al fracaso. Se trata, especialmente, del papel que desempeña el conciliador en cuanto sujeto entre las partes que no asume una función de empeño y esfuerzo en colaborar para que las partes alcancen el acuerdo que ellas quieran y para las que sea el mejor de los acuerdos, velando en todo caso por esa necesidad de equilibrio, respeto y neutralidad entre ellas, sino que durante tiempo al conciliador lo que le motivaba era que se obtuviera un acuerdo, cualquiera que este fuera, sin asumir esa función a la que hemos aludido. En este sentido, a medida que surgió la mediación como evo- 
lución de la conciliación, en la que el mediador necesita aprender a ser buen mediador, a través de los cursos de capacitación que le enseñan a aproximar a las partes, a trabajar con ellas, a convertir el lenguaje negativo en lenguaje positivo, etc. la conciliación va poco a poco relegando su presencia al ámbito intraprocesal y a las regulaciones que en el proceso se ofrecen a esa posibilidad de acuerdo con las partes.

Ello no es óbice a que existe en algunos ordenamientos jurídicos confusión entre mediación y conciliación. Se habla de procedimiento de conciliación en ciertos casos para hacer referencia a la incorporación de unos especialistas que trabajan, tras realizar y aprender, para que sean las partes mismas las que busquen la mejor de sus soluciones y alcancen el acuerdo entre ellas. En ambos casos existe autocomposición, no hay imposición de un tercero, si bien la diferencia entre ambas modalidades autocompositivas estriba en el papel más o menos proactivo que asume el tercero neutral que interviene, no tanto en línea con la provocación a las partes para que lleguen a un acuerdo, sino ayudando a las partes a que sean estas las que, aproximando posiciones, asuman un acuerdo sobre el mismo. En ciertos casos el conciliador puede resultar activo cuando explica a las partes el posible panorama procesal que pueden encontrar de no llegar a un acuerdo, si bien no se trata en mediación de este tipo de actuación, sino de trabajar con ellas, simultánea y singularmente, tratando de que sean ellas mismas las que consensuen y lleguen a un acuerdo, que no necesariamente puede significar el fin de la discordia sino el saber cómo continuar conviviendo con la misma.

\section{(3.2) El ARBitraje}

Si con la mediación y con la conciliación nos hallamos ante medios autocompositivos en los que el tercero colabora y trabaja con las partes pero no resuelve, con el arbitraje nos encontramos ante una fórmula heterocompositiva de resolución de conflictos, en la que el tercero impone la decisión, resuelve el problema de los terceros-partes que acuden al proceso arbitral, y la decisión tiene eficacia de cosa juzgada, exactamente igual que las decisiones que adoptan los órganos jurisdiccionales a través del proceso judicial.

La institución arbitral nació antes de que se institucionalizara el sistema judicial y mucho antes de que comenzara a producirse, de forma casi universal, el fenómeno del fortalecimiento del Poder Judicial. Ello no obstante, fue generándose un cierto recelo entre las clases jurídicas e incluso por los mismos jueces, de tal modo que a lo largo del siglo XX se han adoptado medidas que tendían a controlar lo que los árbitros hacían por los jueces. Desde esa concepción era imposible abogar por el sistema arbitral viable, positivo y útil, si, a la postre, había que terminar sucumbiendo en manos de los jueces. Bastaba observar los recursos contra los 
laudos arbitrales para comprender que los tribunales se convertían en revisadores de la "gestión" arbitral. Es por ello que, aun cuando pervivible en las legislaciones estatales el arbitraje, ha venido experimentando un paseo, en términos cinematográficos hustonianos ${ }^{10}$, hacia su muerte, simultaneado por un ávido amor hacia el sistema judicial.

Para caracterizar al arbitraje debe insistirse en que se trata de una vía procesal -hay proceso, al igual que en el ejercicio de la función jurisdiccional de los jueces ${ }^{11}$, en el que el tercero-árbitro ejerce función jurisdiccional de juzgar o decir el derecho, resolviendo de modo irrevocable, por lo que se trata de una vía heterocompositiva -el tercero interviene imponiendo su decisión-, y en el que, pese a las diversas y múltiples teorías acerca del arbitraje, hoy debe afirmarse que el arbitraje es el arbitraje y esa es su única naturaleza ${ }^{12}$. El fundamento del arbitraje, como en todas las ADR, se halla en la autonomía de la voluntad, en el ejercicio de la libertad, que, en este caso, se formaliza a través del convenio arbitral, en el que dicha voluntad se expresa, no solo respecto de que las disputas se resuelvan mediante arbitraje -que sería el elemento esencial- sino que en ocasiones se determina quién debe resolver, cuándo, en qué idioma, si es posible o no adoptar medidas cautelares por el árbitro, etc. Todas estas cuestiones han venido a incorporarse a las normas de arbitraje, a medida que ha ido cambiando la perspectiva global y nacional respecto de la incorporación en los mecanismos de tutela del ciudadano, del arbitraje.

La situación comienza a cambiar a medida que en las últimas décadas del siglo XX en la mayor parte de los países occidentales, y en gran medida por la influencia del comercio internacional y de la Ley Modelo de CNUDMI/UNCITRAL ${ }^{13}$ de 1985 , se aprueban reformas arbitrales (en España se produce con la Ley de 5 de diciembre de 1988 y la posterior Ley 60/2003, de 23 de diciembre, de Arbitraje). Van poco a poco creciendo los países que asumen la Ley Modelo UNCITRAL de $1985^{14}$, armoni-

10 Nos referimos a la película de John Huston "Paseo por el amor y la muerte".

11 Es importante, en este sentido, diferenciar lo judicial (que hace a la intervención de los jueces) a lo jurisdiccional (que hace a la función, a saber, juzgar y hacer ejecutar lo juzgado, como funciones en el ejercicio reclamado de la tutela efectiva por los ciudadanos). En el arbitraje no hay función judicial sino jurisdiccional en lo que a juzgar se refiere, esto es, a decir el derecho en el caso concreto de modo irrevocable, con efectos de cosa juzgada al igual que las sentencias judiciales.

12 Teoría que puede encontrarse en mis obras: (2010). Derecho Jurisdiccional II (con Montero/ Gómez Colomer/Montón), Valencia: Tirant lo Blanch, ed. 18; y en (2004). Comentarios a la Ley de Arbitraje (AAVV), (coord.: Silvia Barona Vilar), Madrid: Thomson-Civitas.

13 Comisión de las Naciones Unidas para el Derecho Mercantil Internacional.

14 Un texto de soft law, fruto de un complejo proceso de elaboración, que ha supuesto un auténtico hito en el régimen jurídico del arbitraje comercial internacional de los últimos años, como lo demuestra el hecho de que haya servido de base para la reforma o aprobación ex novo de las legislaciones arbitrales de más de 40 países. Estamos, pues, ante un auténtico "texto de referencia", cuyo estudio es imprescindible para entender la realidad del arbitraje comercial internacional de los últimos años. 
zándose las legislaciones sobre arbitraje ${ }^{15}$. Muestra de ese interés creciente y de esa proyección del arbitraje es igualmente la reciente reforma, aun no aprobado definitivamente por el legislador español, en la que se reforma la Ley 60/2003 y cuya aprobación se considera inminente. Se trata del texto de "Ley de reforma de la Ley 60/2003, de 23 de diciembre, de arbitraje y de regulación del arbitraje institucional en la Administración General del Estado", cuyas líneas principales quedarían circunscritas a:

1. La reasignación de las funciones judiciales en relación con el arbitraje, tanto de las funciones de apoyo, como el conocimiento del recurso de anulación del laudo y el exequátur de laudos extranjeros, que permita dar más uniformidad al sistema mediante una "elevación" de determinadas funciones (nombramiento judicial de árbitros, anulación del laudo y el exequátur de los laudos extranjeros), atribuyéndose en el nuevo texto a las Salas de lo Civil y de lo Penal de los Tribunales Superiores de Justicia.

2. A la restricción del arbitraje de equidad, consecuencia de la tramitación paralela del texto sobre mediación. Se entiende que la solución en equidad puede mejor verse desarrollada a través de la mediación, opinión que no compartimos.

3. Se habilita una solución rápida para los supuestos de extralimitación parcial del laudo, de manera que, antes del ejercicio de la anulación por esta causa, se solicitará al árbitro, en el plazo de tres días desde su notificación, que corrija el exceso. Con ello se produce una prórroga de la función arbitral que estará acogida legalmente cuando el texto sea aprobado.

4. Se refuerza la capacidad de los árbitros, su responsabilidad y sus incompatibilidades en relación con la mediación.

5. Se introduce y con ello se incorpora un elemento absolutamente novedoso en el texto, una nueva disposición adicional que se intitula "Controversias juridicas en la Administración General del Estado y sus Organismos públicos", desarrollando a este respecto que las controversias jurídicas relevantes -se entenderán por controversias jurídicas relevantes aquellas que, con independencia de su cuantía generen o puedan generar un elevado número de reclamaciones, que tengan una cuantía económica de al menos 300.000 euros o que, a juicio de una de las partes, sea de esencial relevancia para el interés público- que se susciten entre la Administración General del Estado y cualquiera de los Organismos públicos regulados en el Título III y la disposición adicional novena de la Ley 6/1997, de 14 de abril,

15 Sobre estas cuestiones puede verse el Prólogo a Barona / Espulgues (2004). Legislación básica de Arbitraje, Valencia: Tirant lo Blanch. 
de organización y funcionamiento de la Administración General del Estado, o las Entidades Gestoras y Servicios Comunes de la Seguridad Social, u otras Entidades de Derecho público reguladas por su legislación específica que se determinen reglamentariamente, o entre dos o más de estos Entes, se resolverán por el procedimiento previsto en este precepto, sin que pueda acudirse a la vía administrativa ni jurisdiccional para resolver estas controversias. E igualmente se hace extensible a las controversias jurídicas que se susciten entre las sociedades mercantiles estatales y las fundaciones del sector público estatal con su Ministerio de tutela, Dirección General de Patrimonio u Organismos o entidades públicas que ostenten la totalidad del capital social o dotación de aquellas, salvo que se establezcan mecanismos internos de resolución de controversias.

Para la resolución arbitral de estas controversias se creará una Comisión Delegada, que estará presidida por el titular del Ministerio de la Presidencia, tendrá como vocal nato al titular del Ministerio de Economía y Hacienda, ostentando la secretaría el Ministerio de Justicia. El resto de miembros se determinará reglamentariamente. Resolverá de forma vinculante para las partes, determinando las medidas que cada una de ellas deberá adoptar para solucionar el conflicto o controversia planteados, no siendo recurrible ante los Tribunales de Justicia.

No se aplicará este procedimiento de resolución de controversias a las cuestiones de naturaleza penal, pero sí a las relativas al ejercicio de las acciones civiles derivadas de delitos o faltas; a las cuestiones de responsabilidad contable que sean competencia del Tribunal de Cuentas, sujetas a la legislación específica reguladora de este; a los conflictos de atribuciones entre distintos órganos de una misma Administración pública, que se regularán por sus disposiciones específicas; a las cuestiones de las actuaciones de control efectuadas por la Intervención General de la Administración del Estado, reguladas con carácter específico en la Ley 47/2003, de 26 de noviembre, General Presupuestaria, en la Ley 38/2003, de 17 de noviembre, General de Subvenciones, y demás normas de desarrollo de las mismas.

Todo ello pone de relieve que el arbitraje está vivo y, por ello, que ha ido ganando a poco el puesto que desde la historia de la solución de conflictos vino a cubrir en el ámbito jurídico. Y esta perspectiva que se expone no es solo del ordenamiento jurídico espańol sino que responde a una visión y posición en estos momentos global.

\section{(3.3) LA MEDIACIÓN. SU POSICIÓN EN ALZA}

En el desarrollo de las ADR ha ido poco a poco asumiendo un papel esencial la mediación, convirtiéndose en todos los ordenamientos jurídi- 
cos y en todas áreas, en la mejor de las opciones, siquiera inicialmente, para la gestión del conflicto y en su caso para la evitación del mismo. Es por ello que en la actualidad la mediación tiene incidencia en sectores como familia, negocios, laboral, penitenciaria, vecindad, civil en general, en materia penal, escolar, menores, universitaria, en el sector bancario, en materia de seguros, etc.

En España el auge de la mediación se ha producido en muchos ámbitos, si bien destacaríamos, por su ya experiencia consolidada, la mediación familiar. Repárese que la labor desempeñada en este sector ha sido grande gracias a la aportación legislativa realizada desde el seno de las Comunidades Autónomas. Son ya numerosas las leyes de mediación familiar autonómicas, respondiendo todas ellas a la necesidad de impulsar como mecanismo de pacificación social en el seno de las relaciones familiares a la mediación. Si bien en el ámbito de la familia es donde se generan fricciones que afectan en muchos casos a relaciones jurídicas que van a seguir manteniéndose a pesar de aquellas, no solo se permite la mediación en esas relaciones puramente internas de la familia como núcleo social, sino que también se extiende, en algunas leyes de mediación, a las posibles rupturas, fricciones o desencuentros que pueden darse en las relaciones de la empresa familiar y para las que la idea de la confidencialidad, como elemento esencial predicativo de la mediación, es de alto valor.

Obviamente, más allá de la mediación familiar es indudable que la mediación ha ido ganando terreno en el seno de la solución de los posibles conflictos en sectores como en el consumo -fomentado por la nueva regulación del RD de 2008-, en materia penitenciaria, en la que se parte en muchos casos de proyectos piloto que tratan de aplicarla como vía de solución de conflictos inclusive entre el preso y la institución penitenciaria, en materia laboral, donde la relación entre los sujetos en conflicto van a tener una amplia perdurabilidad e inclusive van a continuar manteniéndose por lo que gestionar aquí el conflicto es mejor que imponer una decisión en la que a la postre va a haber quien se sienta vencedor y quien se sienta vencido... Y también en los últimos años se ha producido un interés creciente en Espańa por la mediación penal, habiéndose llevado a cabo determinados proyectos piloto, juntamente con el Consejo General del Poder Judicial, con el fin de trabajar, de manera voluntaria tanto por los juzgados como por los sujetos implicados, en este modelo de mediación, a la búsqueda futura de una norma habilitante, reguladora de la mediación penal, de sus principios, fases, y completada mediante una regulación estatutaria que especialmente marca el acento en el elemento subjetivo, a saber, el mediador, requisitos para serlo, capacitación, etc.

En ese impulso ha tenido mucho que ver la Unión Europea, que desde las diversas instancias ha venido reforzando la idea de que los Estados miembros deben apostar por la mediación como vía pacífica de resolución o de gestión de los conflictos, y han sido plurales las actividades, a 
los efectos de potenciar en el marco de la Unión Europea estos modelos de solución de problemas que no necesariamente deben pasar por la intervención de los tribunales. Debe destacarse especialmente la Directiva 2008/52/CE, sobre ciertos aspectos de la mediación en asuntos civiles y mercantiles, así como las diversas acciones europeas en las que se insta a los Estados miembros a la incorporación de la mediación en el proceso penal ${ }^{16}$, así como la Recomendación No R (85)11 del Comité de Ministros del Consejo de Europa sobre la posición de la víctima en el marco del derecho Penal y del procedimiento penal, de 28 de junio de 1985 , que recomienda a los Gobiernos de los Estados Miembros examinar las posibles ventajas de los procedimientos de conciliación y mediación, la Recomendación No R(87) 21 del Comité de Ministros del Consejo de Europa sobre la asistencia a las víctimas y la prevención de la victimización de 17 de septiembre de 1987, que recomienda a los Estados Miembros favorecer los experimentos, en el ámbito nacional o en el local, de mediación entre el infractor y la víctima, y evaluar los resultados, observando en particular hasta qué punto sirven a los intereses de la víctima; la Comunicación de la Comisión al Consejo, al Parlamento Europeo y al Comité Económico y Social sobre las víctimas de delitos en la Unión Europea: Normas y medidas, de 14 de julio de 1999, que afirma que la mediación entre el delincuente y la víctima podría ser una alternativa a un procedimiento criminal largo y desalentador, en interés de las víctimas, y posibilita la indemnización del daño o la recuperación de los bienes robados al margen de un procedimiento penal normal, la Recomendación No R (99)19 del Comité de Ministros del Consejo de Europa, relativa a la mediación en materia penal, que establece unos principios que deben tener en cuenta los Estados miembros al desarrollar la mediación en materia penal, la Decisión Marco 2001/220/JAI del Consejo, de 15 de marzo de 2001, relativa al estatuto de la víctima en el proceso penal, que dispone en su artículo 10, que los Estados Miembros "procurarán impulsar la mediación en las causas penales para las infracciones que a su juicio se presten a este tipo de medida" y "velarán porque pueda tomarse en consideración todo acuerdo entre victima e inculpado que se haya alcanzado con ocasión de la mediación en las causas penales". Recomendación No (2006)8, de 14 de junio de 2006, sobre asistencia a las víctimas de las infracciones criminales, en cuyo Anexo, que reemplaza a la Recomendación 21, se ocupa detalladamente de las definiciones de víctima, victimización y victimización secundaria, de la asistencia, del papel de los servicios públicos, de los servicios de asistencia a las víctimas, del acceso efectivo a los recursos jurisdiccionales, de las

16 Para un desarrollo de la mediación penal puede verse mi artículo (2009). "Mediación penal como pieza del sistema de tutela penal en el Siglo XXI. Un paso más hacia la resocialización y la justicia restaurativa”, en Revista de Derecho Penal. 
indemnizaciones acordadas por el Estado, de los seguros públicos y privados, de la protección de la integridad física y psicológica de las víctimas, de la confidencialidad, de la selección y formación del personal de los servicios, de la mediación y de la coordinación y cooperación internacional, etc. ${ }^{17}$.

\section{(3.3.1.) Definición, características y principios de la mediación}

Aun cuando en cada uno de los ámbitos específicos la mediación la regulación debe contemplar las especificidades, hay unas líneas generales y unos principios que permiten definirla y caracterizarla como modelo autocompositivo de solución y/o gestión de los conflictos jurídicos.

\section{(a) Definición}

La mediación es un medio a través del cual interviene un tercero, ajeno al conflicto, asume la función de reunir a las partes y ayudar a resolver sus desacuerdos. Su éxito pasa por un intercambio de información, asumiendo que, por regla general, se inicia la negociación desde la desconfianza, debiéndose limar poco a poco por el mediador, haciéndoles cada vez más partícipes de la técnica mediadora, desbrozando el problema, creando opciones, e instándoles a que propongan soluciones, asumiendo que la decisión debe ser el resultado de una participación de las partes que aceptan su posición y toman un acuerdo como solución a su conflicto. Su figura dependerá en muchas ocasiones que se aminore la hostilidad recíproca o unilateral presente.

Reiteramos, al respecto, la diferenciación existente entre mediación y conciliación. Si bien ambas son dos vías de solución de los conflictos, o de suavización de los mismos, autocompositivas, a saber con participación de un tercero neutral e imparcial que interviene, aun cuando son las propias partes las que "deciden" sobre su conflicto, y no viniendo impuesta la solución por un tercero (heterocomposición judicial o arbitral), la mediación destaca en la actualidad porque en ella el mediador desempeńa la función de acercar posiciones incluso con propuesta de acuerdos solo cuando las partes lo piden, mientras que en la conciliación, las partes se relacionan a través del conciliador, que no hace ningún tipo de propuesta de acercamiento entre las partes; su papel es más pasivo que el mediador y su interés en la conciliación es que se llegue a un acuerdo, sea cual sea este. En ambos casos, la solución se alcanza inter partes, no supra partes.

17 Puede verse Tamarit Sumalla, J.M. (2005). “¿Hasta qué punto cabe pensar victimológicamente el sistema penal?” en Tamarit Sumalla, J.M., (coord.): Estudios de Victimología. Actas del Primer Congreso español de victimología, Valencia: Tirant lo Blanch, pp. 35 y ss. 
La regulación de la mediación es sectorial en nuestro sistema jurídico, si bien la presentación del Anteproyecto de Ley de Mediación por el Gobierno de España este año 2010 ha supuesto ya la voluntad política de conformar un modelo de mediación que permita, por un lado, perfilar los elementos esenciales de la misma, y especialmente que determine los efectos jurídicos más allá de un contrato, a saber, los efectos que en el ámbito procesal va a suponer el acuerdo alcanzado. Esa necesidad de ofrecer una fuerza jurídica especial, más allá del pacto derivado de la autonomía de la voluntad, ha sido una constante en los últimos años, en gran medida por cuanto la intervención en mediación per se no resulta eficiente si no va acompañada de una posibilidad de exigibilidad del acuerdo al que se ha llegado como consecuencia de una negociación en mediación, entendido no como exigibilidad por la vía ordinaria sino como fuerza ejecutiva del acuerdo de mediación. El paso adelante que la legislación nacional proyectada ha realizado es importante en este sentido, por cuanto permite precisamente convertir en título ejecutivo el acuerdo alcanzado en mediación, lo que comporta uno de los principales avances en la regulación de la mediación.

Finalmente, y en punto a la definición de la mediación, es importante determinar que hablar de mediación puede llevarnos a concretar diversas modalidades u objetivos alcanzables a través de la misma, de manera que en unos casos estamos ante un procedimiento de resolución de los conflictos; en otros, una vía para suavizarlos o recomponer las relaciones jurídicas, favoreciendo incluso la propia gestión del conflicto -asumiendo en este caso que el conflicto va a perdurar-, de ahí que no siempre se contemple la posibilidad de mediación como mecanismo de solución de los conflictos, sino como vía de gestión del mismo, considerando que el conflicto inevitablemente va a continuar. Y, en cualquiera de los supuestos, puede convertirse en un medio complementario del proceso, como cauce previo al mismo, o bien sin vinculación a proceso alguno, a saber, el único y aislado mecanismo de planteamiento del conflicto, ora para su solución ora para su gestión. En el primero de los supuestos, cuando la mediación es el paso previo del proceso, este puede serlo judicial o bien arbitral.

\section{(b) Características}

Las características que otorgan singularidad al modelo de mediación son:

1. En primer lugar, la mediación constituye un procedimiento informal y privado de solución de diferencias, basado en todo caso en el principio de la autonomía de la voluntad, salvo que una norma imperativa impulsara la adscripción de un procedimiento de mediación como trámite previo a la existencia de un proceso. Debe ser voluntaria. 
Existen intentos de introducir la mediación obligatoria, lo que, desde mi punto de vista, es condenarla al ostracismo. Debe ser un acto de libertad -con posible recomendación judicial en su caso, pero nunca obligatoria-.

2. Es una fórmula extraprocesal y extrajurisdiccional, que se proyecta en conflictos de diversa índole. El sentido de la diferenciación de ambos conceptos, procesal y jurisdiccional, obedece a su intrínseco significado. En la mediación no hay proceso sino procedimiento, y la función que se desempeña en la mediación no es la de juzgar y hacer ejecutar lo juzgado, propia de la función jurisdiccional, sino la de aproximar a las partes para que sean estas y no el mediador las que alcancen los resultados. De ahí que en el procedimiento de mediación no pueda afirmarse que nos hallamos ante un proceso ni que la función sea la de resolver heterocompositivamente. Es por ello que en la mediación no hay proceso ni jurisdicción.

En la mediación la actuación que se desempeña por el mediador debe efectuarse desde una posición interpartes de acercamiento de las mismas, que no pueda ser objeto de reprochabilidad frente a una posible posición parcial del mediador frente a algunos de los sujetos-parte que intervienen. Esta actuación es lo que reiteradamente hemos venido considerando como autocomposición, en la que el mediador trabaja para que sean las mismas partes las que lleguen a la solución del conflicto, si bien esa actuación es el resultado de un acercamiento más o menos complejo que va a exigir de habilidades y capacidades que solo el mediador puede desempeñar. Su esencia es la flexibilidad, la neutralidad del mediador y por ende la confianza que se despliega para que los que se acercan a la mediación se encuentren cómodos para poder negociar, ceder y acordar, a la postre, una solución consensuada. Pretender convertir la mediación en sucedáneo procesal judicial es uno de los peligros que en estos momentos concurren y que no deben hacerse realidad.

3. La mediación exige una limitada regulación, referida esencialmente a qué es la mediación, cuál es su objetivo, su procedimiento y los elementos esenciales del estatuto del mediador, pero siempre desde la flexibilidad. Así, salvando algunas reglas fundamentales que implican garantías (exigencia de confidencialidad, salvar la presunción de inocencia en temas penales, bilateralidad o audiencia, quizás incluso la fijación de un plazo máximo de duración del procedimiento...) parece recomendable jugar con la idea de la flexibilidad en la conformación del procedimiento, en atención a la materia, las personas (pueden ser plurales, personas físicas y/o jurídicas, etc.), al número de mediadores, a la gravedad o entidad del conflicto, etc.

4. La figura del mediador es la pieza indiscutible de este modelo. Ni la ley estatal ni las autonómicas constriñen a determinada profesión la 
función del mediador. Antes al contrario no es posible, dada la variedad de mediaciones que el ordenamiento jurídico nos ha venido diseñando, desde una visión sectorial, limitar o restringir esta función a unos determinados profesionales. Repárese que los mediadores son "ciudadanos entre los ciudadanos ${ }^{18 "}$, lo que refleja esa necesidad de proximidad y a la vez de sensación de confianza que debe presidir la relación entre los sujetos implicados y los mediadores. Ello no obstante se hace imprescindible que el mediador posea una formación general que le permita desempeñar esta tarea y sobre todo ofrecer garantía a las partes que intervienen en el procedimiento de mediación. La exigencia de capacitación es especialmente relevante. Y es posible configurar la figura del mediador individual o del Servicio de mediación. En todo caso, se dispondrá de un seguro de responsabilidad profesional, que pueda hacer frente a la posible responsabilidad patrimonial que, en su caso, pueda exigirse.

\section{(c) Principios de la mediación}

Aun cuando algunos de los principios que deben predicarse de la mediación quedan intrínsecamente vinculados a las características de la misma y a la propia definición de esta institución, pueden concretarse como principios los siguientes;

1. Voluntariedad. Nadie está ni debe estar obligado ni a acudir, ni a concluir un acuerdo ni a mantenerse en un procedimiento de mediación si no quiere. Responde al punto nuclear de la mediación. Convertir la mediación en obligatoria refuerza su condena al fracaso y otorga a la misma un valor de tutela controlada por el Estado, dirigida por el mismo y que pierde la fuerza de la libertad que la hizo nacer y perdurar ${ }^{19}$.

2. Principio Dispositivo. Puede llevarse a mediación todos los conflictos que surjan en el ámbito de las relaciones disponibles entre las partes, y del mismo modo pueden decidir apartarse del modelo de mediación en cualquier momento.

3. Principio de igualdad. Los sujetos que intervienen deben tener garantizadas la plena igualdad de oportunidades a lo largo del procedimiento, de manera que puedan mantener el equilibrio entre sus posiciones y el respeto debido a la posición mantenida, a sus puntos

SIx, J.F. (1997). Dinámica de la mediación, Barcelona: Paidós, p. 159.

Podríamos reiterar aquello que tantas veces hemos venido reiterando de que el arbitraje es libertad, lo que se hace extensivo igualmente a cualesquiera de las fórmulas ADR que suponen una apuesta clara por una vía no jurisdiccional. Puede verse mi Introducción en el libro BArona VILAR, S. (coord.) (2004). Comentarios a la Ley de Arbitraje, Madrid: Civitas-Thomson. 
de vista, etc., sin que el mediador pueda realizar actuación que genere perjuicio de alguno de ellos o, en su caso, posicionarse a favor de una de ellas, afectando, en consecuencia, el interés de las mismas.

4. Principio de neUtralidad-imparcialidad DE los mediadores. Los mediadores deben mantener un comportamiento neutral e imparcial, a saber, sin posicionarse por una de las partes, asumiendo el papel activo que lleve a colaborar con ambas partes, sin favorecer a una respecto de la otra. Esa función les obliga a no guardar relación alguna ni con el objeto del litigio ni con los sujetos.

5. Principio de Confidencialidad. Una de las mayores riquezas que se ofrecen en el procedimiento de mediación es la de la exigencia de la confidencialidad, no solo de la misma existencia del procedimiento de mediación sino también -obviamente- de su contenido, de manera que ni los mediadores ni las personas que participan en la administración del procedimiento tengan obligación de actuar como testigos en un proceso judicial posterior. De este modo, el principio de confidencialidad queda cubierto. No obstante, y aun siendo la confidencialidad uno de los elementos esenciales del modelo de las $\mathrm{ADR}$, que permite garantizarse a través de la no difusión ni comunicación de lo realizado en estos cauces en posteriores procesos judiciales, el legislador nacional, en su ley proyectada a través del Ministerio de Justicia, ha venido a introducir una serie de supuestos en los que se eximía de esa obligatoriedad de prestar declaración por parte de estos sujetos. Es por ello que en el artículo 11 se excepcionan de esta no obligación de declarar:

a) Cuando las partes de manera expresa acuerden otra cosa en el acta inicial.

b) Cuando, previa autorización judicial motivada, sea necesario por razones de orden público y, en particular, cuando así lo requiera la protección del interés superior del menor o la prevención de daños a la integridad física o psicológica de una persona.

c) Cuando, previa autorización judicial motivada, el conocimiento del contenido del acuerdo sea necesario para su aplicación o ejecución.

d) Cuando así lo establezca la legislación procesal.

Este principio de confidencialidad no solo se refiere al mediador sino que debe hacerse extensivo a cuantos intervienen en él, a saber, los sujetos que acuden a mediación, a quienes les llega la obligación de mantener esta confidencialidad y a los centros de mediación en los que se despliega esta actividad mediadora. La exigibilidad de esta confidencialidad se hace patente a través de la posible responsabilidad que podrá reclamarse en el supuesto de violación de la misma. Es más, su vulneración puede llevar 
inclusive a la inhabilitación para el ejercicio de la mediación en un momento posterior.

\section{(d) Líneas generales del procedimiento de mediación}

Asumidos los principios de flexibilidad, agilidad y no excesivos formalismos, la regulación del procedimiento debe serlo en estos términos. Si la bondad de la mediación es precisamente la frescura y la flexibilidad del sistema frente a un modelo más cerrado y estático como es el proceso judicial, la respuesta abierta del legislador ante el procedimiento es uno de los elementos esenciales para garantizar un buen futuro de la misma. Todo ello siempre con el debido respeto al principio de igualdad de posiciones de los intervinientes y la garantía de la contracción, así como la necesidad de que el mediador actúe bajo el principio de neutralidad y de imparcialidad.

Se destaca, por ejemplo, en el texto proyectado sobre mediación la necesidad de respeto mutuo y de actuación bajo el principio de la buena fe. Se afirma que se garantizará esta conducta de buena fe en la medida en que quede prohibida la interposición de acción judicial o extrajudicial mientras pende el procedimiento de mediación. Y, en todo caso, se les exige, siempre en la medida de lo posible y bajo los límites oportunos de ese buen hacer el que las partes en este procedimiento presten colaboración y apoyo permanente a la actuación del mediador, manteniendo la adecuada deferencia hacia la labor y actividad que desempeña.

Así, en el procedimiento, por tanto, la flexibilidad, la agilidad, la corta duración deben ser los pilares fundamentales sobre los que se desarrolla el mismo, con unos principios esenciales que garanticen el debido respeto, la igualdad de las partes, la posibilidad de ser oídos, la no duración excesiva (en algunos casos incluso puede establecerse límites máximos de duración), etc.

Cuestión especialmente importante en la regulación del mismo es el acuerdo que pueda alcanzarse en mediación, y sobre todo la fuerza jurídica del mismo, siendo una de las cuestiones esenciales de la futura ley de mediación: ¡es un contrato?, ¡en una transacción con posible fuerza jurídico-procesal? Si es contrato, el incumplimiento contractual exige de un proceso posterior y hace ineficaz el esfuerzo y las energías en este procedimiento de mediación. Es importante atribuirle fuerza ejecutiva. Para ello el Estado debe preservar que la obtención de este título ejecutivo se alcance con las garantías de procedimiento y de profesionalidad necesarias. De no atribuirle este valor de título ejecutivo la efectividad de la mediación quedará mermada. Es por ello que habrá que completar la regulación específica de esta nueva ley de mediación con las reformas de las leyes procesales que permitan entrelazar lo que sucede y sus resultados en mediación con el proceso judicial mismo. 


\section{BIBLIOGRAFÍA}

- Barona Vilar, Silvia (2010). Derecho Jurisdiccional II (con Montero/ Gómez Colomer/Montón), Valencia: Tirant lo Blanch, ed. $18^{a}$.

- (2004). Comentarios a la Ley de Arbitraje $(A A V V)$, Madrid: Thomson-Civitas.

- Barona / Espulgues (2004). Legislación básica de Arbitraje, Valencia: Tirant lo Blanch.

- Cappelletti, M. (1993). "Alternative Dispute Resolution Processes Within the Framework of the World-Wide Access-to-Justice Movement", Modern Law Review.

- Katz, L.V. (1993). "Compulsory alternative dispute resolution and voluntarism: two-headed monster or two sides of the coin?", en Journal of Dispute Resolution.

- Lipsky, D.B. \& Seeber, R.L (2004). "Dispute Resolution in the Changing Workplace", en IRRA Proceedings of the 57 Annual Meeting.

- Shamir, Y. (2003). Alternative Dispute Resolution Approaches and Their Application, UNESCO, Technical Documents in Hydrology, PC-CP Series No 7.

- Singer, L.R. (1996). Resolución de conflictos. Técnicas de actuación en los ámbitos empresarial, familiar y legal, Buenos Aires: Paidós.

- Six, J.F. (1997). Dinámica de la mediación, Barcelona: Paidós.

- Tamarit Sumalla, J. M. (2005). “¿Hasta qué punto cabe pensar victimológicamente el sistema penal?” en Tamarit Sumalla, J.M., (coord.): Estudios de Victimología. Actas del Primer Congreso español de victimología, Valencia: Tirant lo Blanch.

- Toharia, J. J. (2001). Opinión pública y justicia, Madrid: Consejo General del Poder Judicial.

- Twining, W. (1993). "Alternative to What? Theories of Litigation, Procedure and Dispute Settlement in Anglo-American Jurisprudence: Some Neglected Classics", Modern Law Review. 